\title{
Serum 25- hydroxy vitamin $D$ levels in pregnant women with increase in parity in Tamilnadu population
}

\author{
C Santhana Lakshmi ${ }^{1}$, Kumar A.N. ${ }^{2}$, Valvekar U.R. ${ }^{3}$ \\ ${ }^{1}$ Dr. Collapancheri Santhana Lakshmi, Associate Professor in Obstetrics and Gynaecology of Karpaga Vinayga Institute of \\ Medical Sciences, Madhurantgam, Tamilnadu, ${ }^{2}$ Dr. Amar Nagesh Kumar, Assistant Professor, Department of Biochemistry, \\ Karpaga Vinayaga Institute of Medical Sciences, Madhurantagam, Tamilnadu, ${ }^{3}$ Dr. Umakant Ramchandra Valvekar, \\ Associate Professor, Department of Obstetrics and Gynecology, B K L. Walawalkar Medical College, Saward, Ratnagari, \\ Maharastra, India.
}

Address for Correspondence: Dr. Umakant Ramchandra Valvekar, Associate Professor, Department of Obstetrics and Gynecology, B K L. Walawalkar Medical College, Saward, Ratnagari, Maharashtra, India. Email: urvalvekar@gmail.com

\begin{abstract}
Introduction: Prevalence of vitamin D deficiency among pregnant women is a preventable and treatable health problem. Studies on vitamin D deficiency in pregnant women reported the adverse effects on maternal health and fetal wellbeing. Utmost attention is required in prevention of vitamin D deficiency among pregnant women. Aim of the present study is to know the status of vitamin D levels in pregnant women of different gravidaand to compare biochemical parameters in pregnant women with increase in parity. Materials and Methods: This is a prospective and observational study. Estimation of serum vitamin D levels was studied in 189 pregnant women. Pregnant females were randomly selected, who attended the antenatal clinic from April 2016 to November 2017. Women with serum 25-hydroxy vitamin D level lower than 10ng/ml were diagnosed as vitamin D deficient. Results: In the present study, the mean serum 25-OH vitamin D of all pregnant women is $16.7 \pm 10.5 \mathrm{ng} / \mathrm{ml}$. Primigravida women had higher $25-\mathrm{OH}$ vitamin $\mathrm{D}(15.4 \pm 10.7 \mathrm{ng} / \mathrm{ml})$ than the second and the third grvida women $(10.5 \pm 8.9 \mathrm{ng} / \mathrm{ml}$ and $9.7 \pm 7.6 \mathrm{ng} / \mathrm{ml}$, both $\mathrm{P}<0.001)$. The $77 \%$ of primigravida women and $55 \%$ of second gravida women had serum 25-OH vitamin D concentrations below $10 \mathrm{ng} / \mathrm{ml}$. Strong association was observed between low vitamin D levels and increase in parity. Conclusion: The high prevalence of vitamin D deficiency in pregnancy calls for unanimous approach to tackle this grave situation by implementing a national strategy for screening, prevention, and treatment of this deficiency.
\end{abstract}

Keywords: Vitamin D deficiency, Prevalence, Primigravida, Multigravida, 25-OH vitamin D, Antenatal women, risk factors.

\section{Introduction}

Vitamin $\mathrm{D}$ is a potent steroid hormone required for calcium metabolism, bone growth and mineralisation. Around $90 \%$ of body vitamin D requirement comes from the action of UV light on skin. The average diet contains only about $10 \%$ of our requirements - insufficient to prevent deficiency. Vitamin D deficiency is the most frequent health problem in many populations across the world. Nowadays, prevalence of vitamin D deficiency is seen in all age groups [1]. If severe enough, it can preclude normal bone mineralization leading to clinical manifestations such as Rickets or Osteomalacia [2].

Vitamin D is a fat-soluble vitamin synthesized from cholesterol. Exposure to sunlight causes production of

Manuscript received: $28^{\text {th }}$ November 2017

Reviewed: $6^{\text {th }}$ December 2017

Author Corrected: $14^{\text {th }}$ December 2017

Accepted for Publication: $20^{\text {th }}$ December 2017

Obsgyne Review: Journal of Obstetrics and Gynecology
Cholecalciferol or Ergocalciferol from 7-dehydrocholesterol. For the activation, vitamin D is hydroxylated to 25-hydroxy vitamin $\mathrm{D}$ in the liver, and in the kidney as $25(\mathrm{OH}) \mathrm{D}$ is further hydroxylated to form 1,25 dihydroxyvitamin $\mathrm{D}\left[1,25(\mathrm{OH})_{2} \mathrm{D}\right]$ [3-5]. The main action of vitamin $\mathrm{D}$ is to maintain the physiological levels of serum calcium and phosphorus. The importance of vitamin D for skeletal development, modulation of calcium homeostasis, bone formation, and resorption has been well described in literature [4-6]. It has also other vital roles in regulation of immune function, cell growth, and inflammation in the body [4-7].

Recent studies on vitamin D deficiency in pregnant women reported the adverse effects on maternal health and fetal wellbeing. These studies further reported that vitamin D deficiency had association with adverse outcomes in pregnancy such as pregnancy loss, 
gestational hypertension, preeclampsia, gestational diabetes, higher rates of caesarean section and preterm delivery etc $[5,7,8]$.Vitamin D deficiency during antenatal period is the origin for future health perils in infants such as low birth weight, neonatal rickets, a risk of neonatal hypocalcaemia, asthma and type 1 diabetes. These studies emphasize the importance of adequate serum levels of vitamin $\mathrm{D}$ in antenatal women [8-10]. If vitamin D deficiency is neglected in antenatal period, damage done by it may be reflected in children at a later stage. Therefore, utmost attention is required in prevention of vitamin D deficiency among pregnant women.

Determination of vitamin D status in the first trimester provides an opportunity for early detection and prophylaxis of vitamin D deficiency that may help to reduce adverse pregnancy outcomes. Aim of the present study is to know the status of vitamin D levels in pregnant women of different parity and to compare other related biochemical parameters in pregnant women with increase in parity.There is limited number of studies done about the vitamin D status in pregnant women from India, especially from south India. Hence the present project was planned.

\section{Materials and Methods}

Study Design and Setting: This is an observational study and consists of 189 pregnant subjects. The study was carried out at department of Obstetrics and Gynecology, during the period of April 2016 to November 2017. The study population consists of 189 pregnant women who attended to the antenatal clinic for their routine checkup. The study was approved by the Institutional Ethics Committee. A written informed consent was obtained from all participants after explaining the purpose of the study.

Inclusion criteria: Pregnant women ages between 19 28 years with singleton pregnancies and a live fetus with gestational age 28 weeks were included in the study.

Exclusion criteria: Pregnant women with known history of rheumatoid arthritis, thyroid, adrenal, or parathyroid diseases, hepatic or renal failure, bone disorder, type 1 diabetes mellitus, and multiple pregnancies were excluded from the study.

\section{Results}

A total of 189 pregnant women with gestational age of 28 weeks and more were recruited for the study. The mean age of the pregnant women was $23.7 \pm 4.5$ years. In total, $64 \%(\mathrm{n}=121)$ of them were in the age group of $19-24$ years. About $30 \%$ of the total pregnant women were of second gravida and $16 \%$ were of $3^{\text {rd }}$ gravida. The mean serum $25-\mathrm{OH}$ vitamin $\mathrm{D}$ level of the pregnant women level of primigavida women was $15.4 \pm 10.7 \mathrm{ng} / \mathrm{ml}$, the second gravida women had serum $25-\mathrm{OH}$ vitamin D concentration of $10.5 \pm 8.9 \mathrm{ng} / \mathrm{ml}$ while that of third gravida women was $9.7 \pm 7.6 \mathrm{ng} / \mathrm{ml}$ (Table 1). It is evident, from table 1 that there is a strong inverse relation between vitamin D and gravida in this population. Further serum calcium significant difference in the mean vitamin D levels among pregnant women with gravida 1 , gravida 2 and gravida 3.A $\mathrm{p}$ value $<0.05$ was considered as statistically significant.

Sampling collection and methods: Blood was collected by antecubital vein puncture from the subjects and samples were centrifuged at $3500 \mathrm{rpm}$ for $10 \mathrm{~min}$ at room temperature for separating the serum. Serum samples were analyzed for $25-\mathrm{OH}$ vitamin D levels, calcium and phosphorous. Serum samples with vitamin D levels less than $10 \mathrm{ng} / \mathrm{ml}$ were considered as deficient of vitamin D [8-10].

Serum calcium was estimated by Arsenazo III method and erum phosphorous was estimated by phosphomolybdate for semi-automated biochemistry analyzer. Vitamin D status was assessed by measuring serum concentration of 25-OH vitamin D which has a reasonably long half-life in circulation. Measurement of serum 25-OH vitamin D (Biomeriux) hormone analyzer.

Based on the results obtained, vitamin D status was categorized into three groups.Group I, as serum 25(OH)D levels $<10 \mathrm{ng} / \mathrm{ml}$, group II between 10-29 $\mathrm{ng} / \mathrm{ml}$, and group III 30-100 ng/ml, indicating vitamin D deficiency, vitamin D insufficiency and vitamin D sufficiency respectively [4 -6,8-10]. The gestational age at delivery was determined by menstrual dating, while the ultrasound estimates of gestational age were used in women that had missed or uncertain dates.

Statistical analysis: Data was presented as mean \pm standard deviation (SD) and as percentages for categorical variables. Continuous variables were compared between groups by independent samples $t$ tests for normally distributed variables. The data collected were subjected to statistical tests of mean and standard deviation utilizing the SPSS-16.0 version. To compare the mean serum $25-$ $\mathrm{OH}$ vitamin $\mathrm{D}$ levels among pregnant women of different parity, one-way analysis of variance (ANOVA) was utilized.

The multiple comparison testswas carried out to identify 
Original Research Article

and phosphorous levels were also compared in primi, second and third gravida women. Serum calcium levels were decreased with increase in parity while phosphorous levels were increased with increase in parity (Table 1). Further logistic regression analysis revealed that women with second or third gravida were at a 1.69 times higher risk of vitamin D deficiency (P $<$ 0.001 ) compared to the primigravida women (odds ratio $1.71 ; 95 \%$ confidence interval: $1.6-2.2, \mathrm{P}<0.001$ ).

Table-1: Serum vitamin D, calcium and phosphorous levels of pregnant women according to parity.

\begin{tabular}{|c|c|c|c|c|}
\hline Parity & $\begin{array}{c}\text { Number of Cases } \\
(\mathbf{n = 1 8 9})\end{array}$ & $\begin{array}{c}\text { 25- OH Vitamin D } \\
\text { conc. } \mathbf{( n g / m l )}\end{array}$ & Calcium & Phosphorous \\
\hline Primigravida & $102(54 \%)$ & $15.4 \pm 10.7$ & $8.3 \pm 1.2$ & $3.9 \pm 0.5$ \\
\hline $2^{\text {nd }}$ Gravida & $57(30 \%)$ & $10.5 \pm 8.9$ & $7.9 \pm 0.8$ & $4.4 \pm 0.7$ \\
\hline $3^{\text {rd }}$ Gravida & $30(16 \%)$ & $9.7 \pm 7.6$ & $7.5 \pm 0.6$ & $5.3 \pm 0.9$ \\
\hline
\end{tabular}

Table-2: Distribution of pregnant women according to serum vitamin D levels.

\begin{tabular}{|c|c|c|}
\hline Vitamin D status & n (\%) 189 & Mean \pm SD $(\mathbf{n g} / \mathbf{m l})$ \\
\hline Vitamin D deficiency $(<10 \mathrm{ng} / \mathrm{ml})$ & $89(47 \%)$ & $9.0 \pm 3.4$ \\
\hline Vitamin D insufficiency $(10-29 \mathrm{ng} / \mathrm{ml})$ & $74(39 \%)$ & $13.5 \pm 5.7$ \\
\hline Vitamin D sufficiency $(30-100 \mathrm{ng} / \mathrm{ml})$ & $26(14 \%)$ & $21.9 \pm 9.8$ \\
\hline Number of cases & 189 & $16.7 \pm 10.5$ \\
\hline
\end{tabular}

Table-3: Mean values of biochemical parameters in pregnant women according to vitamin D status

\begin{tabular}{|c|c|c|c|}
\hline & Deficient & Insufficient & Sufficient \\
\hline Number of women (n=189) & 89 & 74 & 26 \\
\hline $25-$ OH vitamin D (ng/ml) & $9.0 \pm 3.4^{*}$ & $13.5 \pm 5.7^{*}$ & $21.9 \pm 9.8^{*}$ \\
\hline Calcium (mg/dl) & $7.7 \pm 0.5^{*}$ & $8.2 \pm 0.4^{*}$ & $8.9 \pm 0.6^{*}$ \\
\hline Phosphorous (mg/dl) & $5.8 \pm 0.7^{*}$ & $4.9 \pm 0.3^{*}$ & $4.2 \pm 0.7^{*}$ \\
\hline
\end{tabular}

${ }^{*} \mathrm{p}$ value $<0.0001$ highly significant (odds ratio $1.71 ; 95 \%$ confidence interval: $1.6-2.2, \mathrm{P}<0.001$ ).

The mean serum $25-\mathrm{OH}$ vitamin D level of all the pregnant women was $16.7 \pm 10.5 \mathrm{ng} / \mathrm{ml}$. About $47 \%$ ( $\mathrm{n}=89$ ) of the pregnant women had serum $25-\mathrm{OH}$ vitamin D levels $<10 \mathrm{ng} / \mathrm{ml}$ (Table 2). There was a significant decrease $(\mathrm{P}<0.01)$ in serum vitamin D level with the increase in parity. Pregnant women with $2^{\text {nd }}$ and $3^{\text {rd }}$ gravida had a significantly lower serum vitamin D level compared to primigravida women (Table 1).

Table 3 shows the mean values of serum $25-\mathrm{OH}$ vitamin $\mathrm{D}$, calcium and phosphorous levels according to the vitamin $\mathrm{D}$ status in pregnant women. It was found that serum calcium levelwasalso found low, while phosphorous level was high in vitamin D deficient pregnant women when compared to vitamin D sufficient pregnant women. This difference is statistically significant $(\mathrm{p}<0.0001)$.

\section{Discussion}

This study investigated the relationship between serum vitamin Dstatus and increase in parity. Since circulating 25-OH vitamin D represents the best indicator of vitamin D status of anindividual [10]. Therefore, in this study, serum 25-OH vitamin D level was opted to determinevitamin $\mathrm{D}$ status. In the present study, it was found that $25-\mathrm{OH}$ serum vitamin $\mathrm{D}$ levels in primigravida women weresignificantly higher than that of second and third gravida women. The increase in circulating $25-\mathrm{OH}$ vitamin D levels during the first-trimester pregnancy is consistent with a prior report thatreported that $1,25(\mathrm{OH})_{2}$ Obsgyne Review: Journal of Obstetrics and Gynecology vitamin D levels are more than 2-fold those of anongravid adult by 12 weeks of gestation [11]. Although the $1,25(\mathrm{OH})_{2} \mathrm{D}$ was tested in this study. However, during pregnancy, 25-OH vitamin $\mathrm{D}$ diffuses across the placental barrier, whereas $1,25(\mathrm{OH}) 2$ Ddoes not readily cross placenta $[12,13]$.

The locally synthesizing $1,25-\mathrm{OH}$ vitamin $\mathrm{D}$ in maternal decidual cells depends on available $25-\mathrm{OH}$ vitamin $\mathrm{D}$ in circulation as a substrate for $1 \alpha$-hydroxylase [14]. It demonstrated that adequate $25-\mathrm{OH}$ vitamin $\mathrm{D}$

Available online at : www.medresearch.in 53 | P a g e 
concentrations wereessential during pregnancy. Vitamin $\mathrm{D}$ deficiency in the mothercould be vertically transmitted to the fetus [12-15].

In the present study high prevalence of vitamin D deficiency (47\%) and vitamin d insufficiency (39\%) was found in pregnant women. This could be because of poor or inadequate intake dietary intake and higher skin pigmentation. The present study results are comparable to the study conducted by Sharma et al., [16] who found that the prevalence of vitamin D deficiency in pregnant females in North Indian population was $93 \%$.

The prevalence of vitamin D deficiency was comparatively less in studies conducted by Ravinder et al., [17] Bartoszewicz et al., [18] and Vandevijvere et al., [19]. In this study, vitamin D deficiency and insufficiency were found to be higher in multigravida as compared to primigravida. This could be due to repeated cycles of pregnancy and lactation in multigravida. In a study reported by Choi et al, [20] primigravida women had severe vitamin D deficiency in about $75.4 \%$ cases, and in multigravida, vitamin D deficiency was reported in $80.8 \%$ cases.

The screening maternal vitamin D status, vitamin D supplementation during pregnancy and the effects of the deficiency on offspring are controversial. The importance of adequate vitamin $\mathrm{D}$ stores during pregnancy and the risk of vitamin $\mathrm{D}$ deficiency has been emphasized by multiple authority bodies in western countries including, UK Department of Health and Canadian Paediatric Society. However, the American College of Obstetrics and Gynaecology has not supported screening all pregnant women for vitamin D deficiency [21 -22].

\section{Conclusion}

The findings of the present study indicate that there is a high prevalence of vitamin D deficiency among pregnant women of South Indian population. To tackle this grave situation, there is a need for conducting multicentric studies as a national program for screening, prevention, and treatment of this vitamin D deficiency among pregnant women ofIndian population.Programs need to be developed to increase the awareness of this problem among people and to provide adequate doses of vitamin D supplements to pregnant women.

Acknowledgements- We would like to extend our thank Dr Viswanathan, Professor and HOD Department of Obstetrics and Gynaecology, Karpaga Vinayaga Institute of Medical Sciences, Tamilnadu for his support in accomplishing this project.

\section{Funding: Nil, Conflict of interest: Nil Permission from IRB: Yes}

\section{References}

1. Palacios C, Gonzalez L. Is vitamin D deficiency a major global public health problem? J Steroid Biochem Mol Biol. 2014 Oct;144 Pt A:138-45. doi: 10.1016/j. jsbmb. 2013.11.003. Epub 2013 Nov 12.

2. Lapillonne A. Vitamin D deficiency during pregnancy may impair maternal and fetal outcomes. Med Hypotheses. 2010 Jan; 74(1):71-5. doi: 10.1016/j.mehy. 2009. 07. 054. Epub 2009 Aug 18.

3. O'Riordan MN, Kiely M, Higgins JR, Cashman KD. Prevalence of suboptimal vitamin D status during pregnancy. Ir Med J. 2008 Sep;101(8):240, 242-3.

4. Harris A. Vitamin D Deficiency in Pregnant Women at a Tertiary Hospital in Western Sydney. Obstet GynecolInt J.2017;7(1):00234.DOI:10.15406/ogij.2017.07.00234.

5. Theodoropoulos C, Demers C, Delvin E, Ménard D, Gascon-Barré M. Calcitriol regulates the expression of the genes encoding the three key vitamin D3 hydroxylases and the drug-metabolizing enzyme CYP3A4 in the human fetal intestine. Clin Endocrinol (Oxf). 2003 Apr;58 (4): 489-99.

6. Andersen LB, Jørgensen JS, Jensen TK, Dalgård C, Barington T, Nielsen J, Beck-Nielsen SS, Husby S, Abrahamsen B, Lamont RF, Christesen HT. Vitamin Dinsufficiency is associated with increasedrisk offirsttrimestermiscarriage in the Odense Child Cohort. Am J Clin Nutr. 2015 Sep; 102(3):633-8. doi: 10.3945/ajcn.114. 103655. Epub 2015 Jul 15.

7. Flood-Nichols SK, Tinnemore D, Huang RR, Napolitano PG, Ippolito DL. Vitamin D deficiency in early pregnancy. PLoS One.2015 Apr 21; 10(4): e0123763. doi:10.1371/journal.pone.0123763.e Collection 2015.

8. Ota K, Dambaeva S, Han AR, Beaman K, GilmanSachs A, Kwak-Kim J. Vitamin D deficiency may be a risk factor for recurrent pregnancy losses by increasing cellular immunity and autoimmunity. Hum Reprod. 2014 Feb;29(2):208-19. doi: 10.1093/humrep/det424. Epub 2013 Nov 24.

9. Ghadimi R, Esmaeilzadeh S, Firoozpour M, Ahmadi A. Does vitamin $\mathrm{D}$ status correlate with clinical and biochemical features of polycystic ovarysyndrome in high school girls? Caspian J Intern Med 2014; 5(4):202-8.

Available online at : www.medresearch.in 54 | P a g e 


\section{Original Research Article}

10. Rosen CJ. Clinical practice. Vitamin D insufficiency. N Engl J Med. 2011 Jan 20;364(3):248-54. doi: 10.1056/ NEJMcp1009570.

11. Wagner CL, Taylor SN, Johnson DD, Hollis BW. The role of vitamin $\mathrm{D}$ in pregnancy and lactation: emerging concepts. Womens Health (Lond). 2012 May;8(3):323-40. doi: $10.2217 /$ whe.12.17.

12. Shin JS, Choi MY, Longtine MS, Nelson DM.Vitamin Deffects on pregnancy and the placenta. Placenta. 2010 Dec;31(12):1027-34. doi: 10.1016/j.placenta.2010.08.015. Epub 2010 Sep 22.

13. Adams JS, Hewison M.Extrarenalexpression of the 25-hydroxyvitamin D-1-hydroxylase. Arch Biochem Biophys. 2012 Jul 1; 523(1):95-102. doi: 10.1016/j. abb. 2012.02. 016. Epub 2012 Mar 14.

14. Hewison M, Burke F, Evans KN, Lammas D, Sansom DM, Liu $P$ et al. Extra-renal 25-hydroxyvitamin D 1alpha-hydroxylase in human health and disease. J Steroid BiochemMol Biol. 2007; 103:316-321.

15. Weisman Y, Harell A, Edelstein S, David M, Spirer Z, Golander A.1 alpha, 25-Dihydroxyvitamin D3 and 24,25dihydroxyvitamin D3 in vitrosynthesis by humandecidua and placenta. Nature. 1979 Sep 27;281(5729):317-9.

16. Sharma S, Kumar A, Prasad S, Sharma S. CurrentScenario of Vitamin D Status During Pregnancy in North Indian Population. J ObstetGynaecolIndia. 2016 Apr; 66 (2):93-100. doi: 10.1007/s13224-014-0658-5. Epub 2015 Jan 21.
17. Ravinder SS, Deepika C, Padmavathi R, Balakrishnan $\mathrm{K}$, Vijayaraghavan J. Occurrence of vitamin D deficiency in pregnant women in South India - A preliminary study. Int J Pure ApplBiosci. 2015; 3(2):291-6.

18. Bartoszewicz Z, Kondracka A, KrasnodebskaKiljańska M, Niedźwiedzka B, Popow M, Ambroziak U, Bednarczuk T. Vitamin D insufficiency in healthy pregnant women living in Warsaw. Ginekol Pol. 2013 May;84(5):363-7.

19. Vandevijvere S, Amsalkhir S, Van Oyen H, MorenoReyes R. High prevalence of vitamin D deficiency in pregnant women: A national cross sectional survey. PLoS One. 2012; 7(8):e43868.https://doi. org/10.1371/journal. pone. 0043868 .

20. Choi R, Kim S, Yoo H, Cho YY, Kim SW, Chung JH, Oh SY, Lee SY.Highprevalence of vitamin D deficiency in pregnantKoreanwomen: the first trimester and the winterseason as risk factors for vitamin D deficiency. Nutrients. 2015 May 11;7(5):3427-48. doi: 10.3390/nu 7053427.

21. Steer PJ. Is vitamin D supplementation in pregnancy advisable? Lancet. 2013 Jun 22; 381 (9884): 2143-5. doi: 10.1016/S0140-6736(13)60098-7. Epub 2013 Mar 19.

22. De-Regil LM, Palacios C, Ansary A, Kulier R, PeñaRosas JP. Vitamin D supplementation for women during pregnancy. Cochrane Database Syst Rev. 2012 Feb 15; (2): CD008873. doi: 10.1002/14651858. CD008873. pub2.

\section{How to cite this article?}

C Santhana Lakshmi, Kumar A.N, Valvekar U.R. Serum 25- hydroxy vitamin D levels in pregnant women with increase in parity in Tamilnadu population. Obs Rev:J obstet Gynecol 2017;3(4):51-55.doi:10.17511/joog.2017.i04.04. 